\title{
High level of aB-crystallin contributes to the progression of osteosarcoma
}

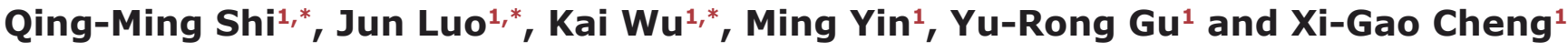 \\ ${ }^{1}$ First Department of Orthopedic Surgery, The Second Affiliated Hospital of Nanchang University, Nanchang, Jiangxi, PR \\ China \\ * These authors have contributed equally to this work
}

Correspondence to: Xi-Gao Cheng, email: cxg2015@163.com

Keywords: osteosarcoma, aB-Crystallin, invasion, MMP-9, prognosis

Received: June 24, $2015 \quad$ Accepted: November 21, 2015

Published: January 17, 2016

\section{ABSTRACT}

Accumulating evidences indicate the elevated expression of aB-Crystallin (Cryab) is implicated in tumorigenesis. However, the expression and biologic role of Cryab in osteosarcoma (OS) are still unknown. In this study, we showed that Cryab expression was elevated in OS tissues and cell lines, and down-regulation of Cryab in MG-63 and U-20S cells led to a decline in the cells' aggressiveness, and reduced secretion of matrix metalloproteinase-9 (MMP-9) in vitro, and lower metastasis potential in vivo. Further study indicated that the Cryab expression was positively associated with the activity of ERK1/2 which is responsible for the cells' aggressiveness and MMP-9 secretion. Clinically, our data confirmed that the high level of Cryab was associated with shorten survival and tumor recurrence for the postoperative OS patients. Together, our results indicate that high level of Cryab is a new adverse outcomes marker for OS patients and may be used as a new therapeutic target.

\section{INTRODUCTION}

Osteosarcoma (OS) is the most frequent malignant bone tumor in children and young people [1]. Although the overall survival of patients with high-grade OS has been markedly improved over the past decades [2], the recurrence for this disease still occurs in approximately 30 - 40 percent of patients with non-metastatic OS, furthermore, almost 80 percent of the OS patients with metastasis at the time of diagnosis will recur $[3,4]$. Generally, the standard multimodal therapy failure for OS is associated with a very poor prognosis $[5,6]$. Therefore, it is very important and meaningful to screen for novel molecular markers and deepen our understanding of the molecular mechanisms linked to OS metastasis and invasion.

$\alpha \mathrm{B}$-crystallin (Cryab), a human small heat-shock proteins (sHsp), was first identified as one of the structure member of the vertebrate eye lens. Cryab presents with high levels in the lens, while low in other tissues including the cardiac and skeletal muscle, kidney, and brain [7]. The functions of Cryab have been found to be involved in a variety of processes including cytoskeletal assembly, remodeling and stabilization, apoptosis inhibition, and modulation of membrane fluidity [7]. In recent years, the increasing expression of Cryab have been identified to be related to a number of pathologies including cancer, with elevated expression of Cryab observed in several cancers, for example, a high level of Cryab has been found to be a prognostic marker in breast, renal, thyroid, nasopharyngeal, hepatocellular and lung cancers [8-11]. Furthermore, the up-regulation of Cryab expression seems to be associated with oncogenic transformation in basallike breast cancer, and induces hepatocellular carcinoma cells epithelial-mesenchymal transition [9], In addition, the high level of Cryab was reported to be associated with cell apoptosis resistance, enhance cell survival under the oncogenic stress, growth factor starvation, chemotherapy, and other cellular stressors [12]. Given the key role of Cryab in human cancers development, further study of the role and mechanism of Cryab in OS is urgently needed.

The purpose of this experiment was to check the Cryab expression in OS cells, and in OS and adjacent nontumorous tissues, as well as assessing the role and mechanisms of Cryab in biological behaviours of OS cell lines through Cryab interference and cDNA transfection. Finally, the relationships between the expression of Cryab and clinical features and survival in OS patients were investigated. 


\section{RESULTS}

Cryab is elevated expression in OS tissues

Expression of Cryab was examined by real timePCR (qRT-PCR) in OS and adjacent nontumorous tissues. Low expression of Cryab was detected in nontumorous tissues compared with OS tissues. As shown in Figure 1A and $1 \mathrm{~B}$, the mean $\Delta \mathrm{Ct}$ value of Cryab expression was 2.68 \pm 0.64 and varied significantly in OS samples (range 1.43 - 3.67), while mean expression level was only $1.46 \pm 0.47$ in adjacent nontumorous samples (range $0.87-2.53$ ). The difference in Cryab expression between OS and adjacent nontumorous samples was statistically significant $(p<$
0.01). Immunohistochemistry also showed a high level of Cryab in OS samples compared with the adjacent nontumorous tissues (Figure 1C).

\section{Cryab promotes metastasis and invasion of OS in} vitro and in vivo

To explore the biological roles of Cryab in OS, we firstly evaluated the Cryab expression in $h F O B 1.19$, Saos, HOS, U-2OS and MG-63 cell lines, and found that Cryab expression in OS cells was higher than that in $h F O B 1.19$ cells at the level of mRNA and protein $(p<0.05)$. Then, MG-63 and U-2OS cells were transfected with pGPU6GFP-vshRNA-Cryabs. Of three vshRNA-Cryabs tested, \#2 was testified by qRT-PCR and western blotting for
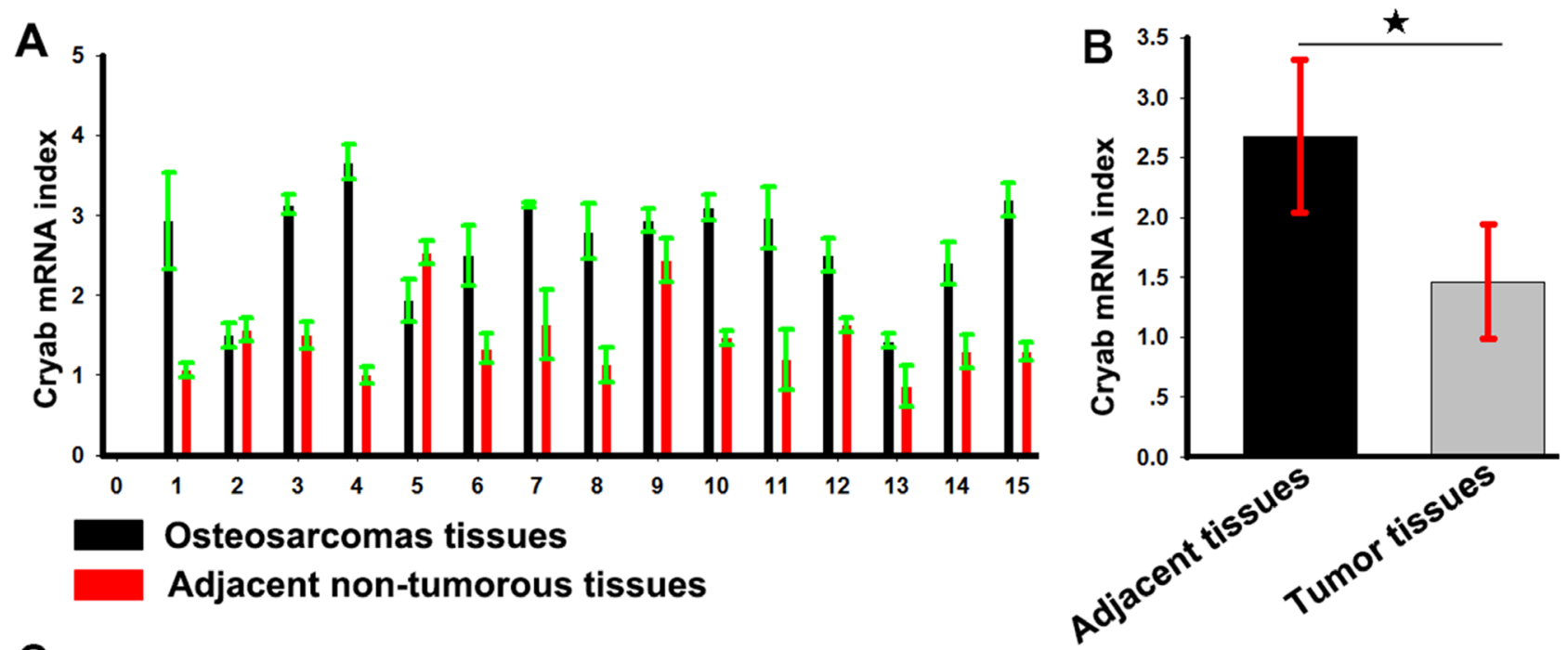

C

Patient 1

Patient 2
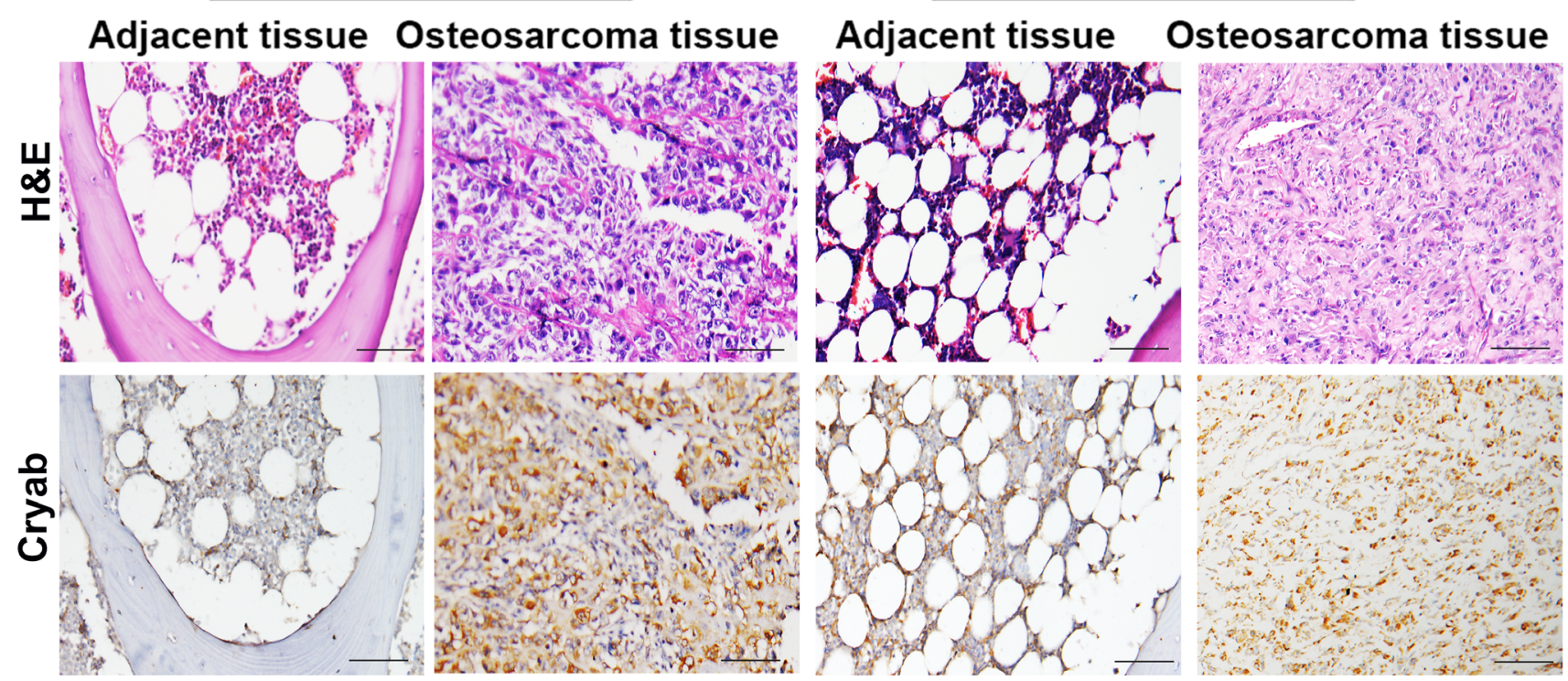

Figure 1: Cryab is elevated expression in OS tissues. A. The expression of Cryab mRNA in OS samples and the adjacent nontumorous samples; B. a histogram showed Cryab mRNA in OS samples and the adjacent nontumorous samples $(p<0.05)$; C. Hematoxylin-eosin staining and immunostaining of Cryab in tumor and the adjacent nontumorous samples $(\mathrm{bar}=200 \mu \mathrm{m})$. 
the most efficient interference of Cryab (Figure 2A, 2B and C) and chosen for further study. The scratch assay presented that a clear delay in the wound closure rate of shRNA-Cryab-MG-63/U-2OS cells was found at $24 \mathrm{~h}$, compared with MG-63/U-2OS-Mock cells (Figure 2D). The transwell assay showed that the down-regulation of Cryab expression inhibited the invasiveness of MG63 and U-2OS cells (Figure 2F). However, the OS cells proliferation were not inhibited by the interference of Cryab ( $p>0.05$, Figure 2E). In vivo analysis showed that the tumor volumes of in the shRNA-Cryab-MG-63 or U-2OS group were smaller compared to their controls ( $264 \pm 35$ vs. $482 \pm 64$ and $358 \pm 56$ vs. $613 \pm 109, p<$ 0.05 , Figure $2 \mathrm{H}$ ), and the incidences of lung metastasis were $40 \%$ in the shRNA-Cryab-MG-63/U-2OS groups compared to $100 \%$ in the control groups (Figure $2 \mathrm{G}$ and Supplementary Figure 1). These results indicated that up-regulation of Cryab was along with the increased metastatic potential of OS cells.
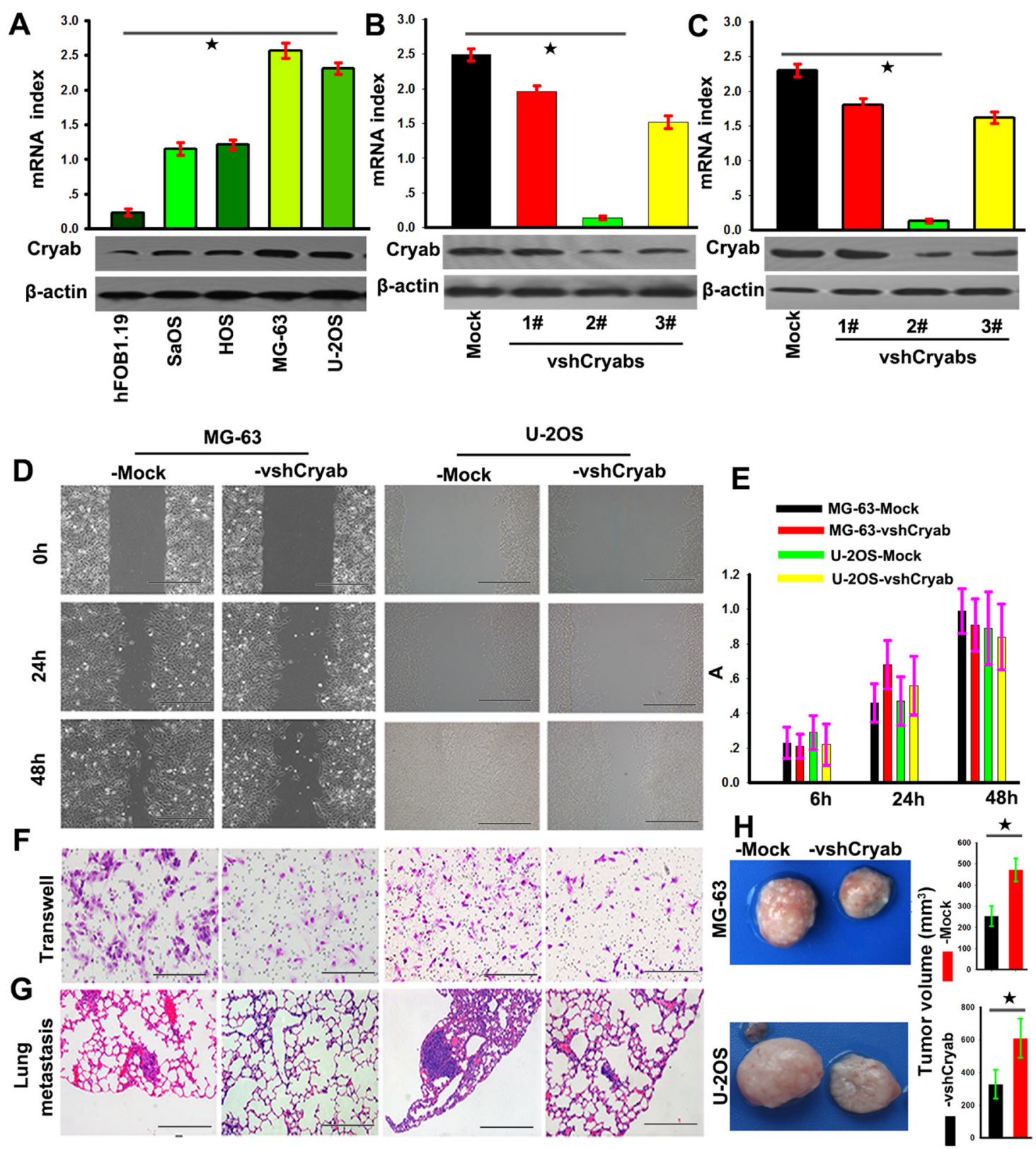

Figure 2: Cryab promoted the invasion and metastasis of OS cells in vitro and vivo. A. RT-PCR and immunoblotting analyzed the expression of Cryab in $h F O B 1.19$, MG-63, U-2OS, Saos and HOS cell lines $(p<0.05)$; (B and C) The expression of Cryab were regulated in MG-63 and U-2OS cells by RNA interference; D. The wound-healing assay revealed that an evident delay in the wound closure rate of MG-63/U-2OS-vshRNA-Cryab cells was found at 24 and 48h, compared with MG-63/U-2OS-Mock cells (bar = $100 \mu \mathrm{m})$; E. The down-regulation of Cryab has no influence on cell proliferation $(p>0.05)$; F. Matrigel invasion assays showed that down-regulation of Cryab was accompanied by a descend invasion of OS cells ( $b a r=100 \mu \mathrm{m})$; G. Serial sections from mouse lung showed the metastasis ability of cancer cells expressing different Cryab $(\mathrm{bar}=50 \mu \mathrm{m})$; H. The tumor volume of cancer cells expressing different level of Cryab. 
High level of cryab induces OS progression via upregulation of MMP9 expression through ERK1/2 signaling

Matrix metalloproteinases (MMPs) have always been with cancer cell invasion and metastasis [13]. Here, we tried to determine the effect of Cryab on the secretion and expression of MMP-2 and 9. Gelatinase activity assays displayed that the expression of Cryab positively associated with the secretion and expression of MMP9, but not MMP-2 (Figure 3A). According to a previous
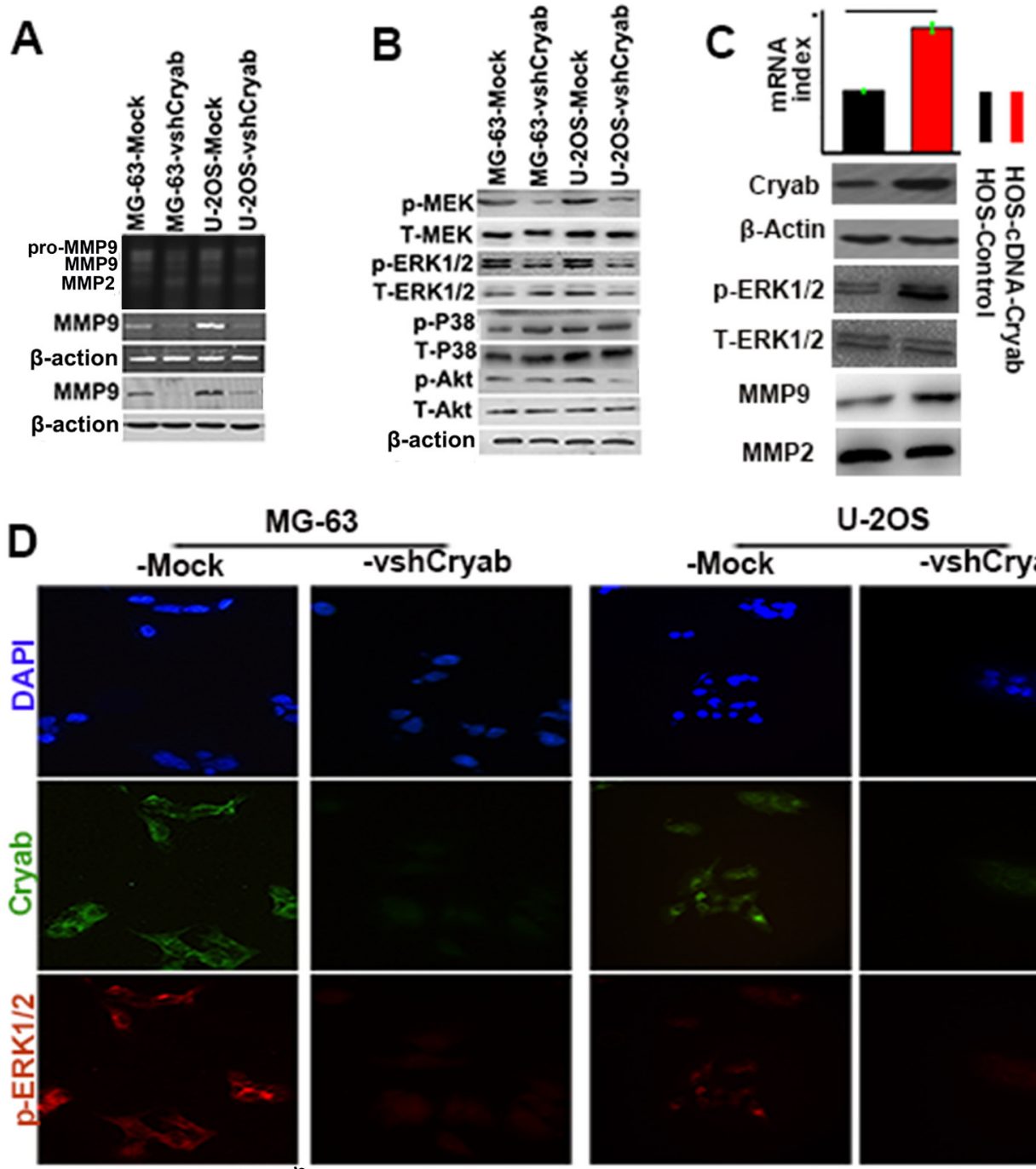

MG-63
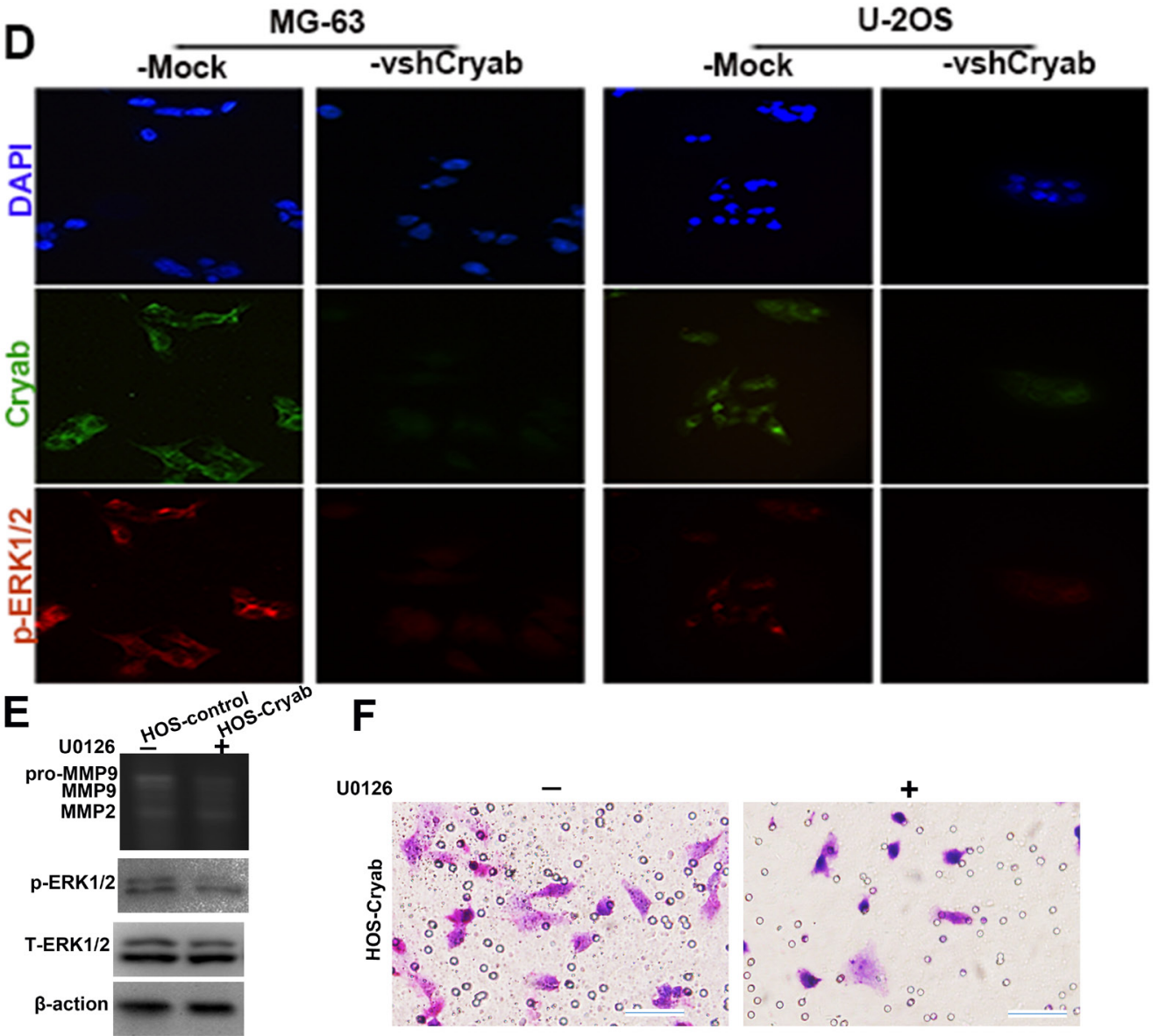

$\mathbf{F}$

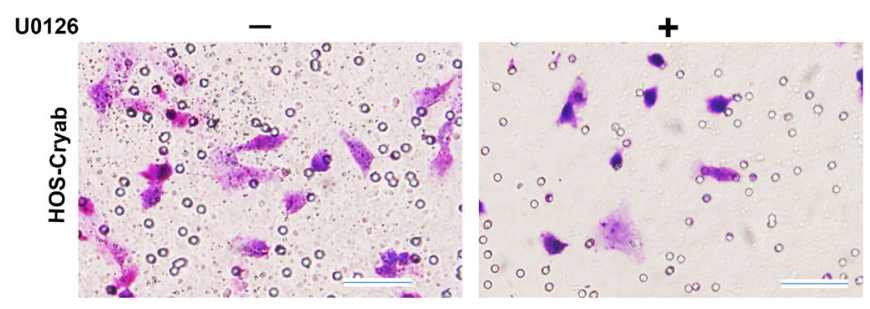

Figure 3: High level of Cryab induces OS progression via up-regulation of MMP9 expression through ERK1/2 signaling. A. The secretion and expression of MMP9 were inhibited by the Cryab specific RNA interference in OS cells; B. The phosphorylation level of MEK and ERK1/2 were reduced significantly in MG-63/U-2OS-vshRNA-Cryab cells, compared with MG-63/U-2OS-Mock cells; C. The level of ERK1/2 activity was elevated, and the expression of MMP9 were up-regulated by Cryab cDNA transfection in HOS cells; D. Immunofluorescent staining showed that the expression of Cryab was in line with the activation of ERK1/2; E. The inhibition of ERK1/2 phosphorylation by U0126 was associated with the inhibition of secretion of MMP9 and OS cells invasion $($ bar $=200 \mu \mathrm{m})$. 
report concerning the mechanisms of Cryab promotion of cancer progression, the amplitude of phosphorylation of MEK, p38, ERK1/2 and Akt in shRNA-Cryab-MG$63 / \mathrm{U}-2 \mathrm{OS}$ cells were compared to their corresponding matched cells. As shown in Figure 3A, the elevated levels of MEK and ERK1/2 were detected in both MG-63/U2OS-Mock cells compared with the shRNA-Cryab-MG63/U-2OS cells, while the p38 phosphorylation was not changed (Figure 3B). Immunofluorescent staining showed that the interference of Cryab in shRNA-Cryab-MG-63/U2OS cells down-regulated the level of phosphorylation of ERK1/2 compared with the Mock-MG-63/U-2OS cells (Figure 3D).

In order to identify the signaling pathways that might contribute to the observed phenotypic changes, we up-regulated the Cryab expression in HOS cells by transfecting Cryab cDNA, we found that the phosphorylation of ERK was much higher in HOScDNA-Cryab cells, and increased the secretion of MMP9 compared with HOS-Mock cells (Figure 3C). Furthermore, U0126-exposure resulted in an evident inhibition of MMP-9 secretion and cells invasion (Figure 3E). These results indicate that ERK1/2 hyperactivation appears to be pivotal for the appeared Cryab-mediated phenotypic characteristics of OS cells.

\section{Expression of Cryab was positively associated with malignant phenotypes of OS by immunohistochemistry}

Positive Cryab staining was detected in the cytoplasm of tumor cells and showed substantial heterogeneity in the dissimilar tumor specimens (Figure 4A). Cryab ${ }^{\text {high }}$ accounted for $41.67 \%$ (15/36) of the total number of patients. Agree with a preceding report [20], patients with high Cryab expression increased chance to exhibit aggressive features. As shown in Table 1, Cryab ${ }^{\text {high }}$
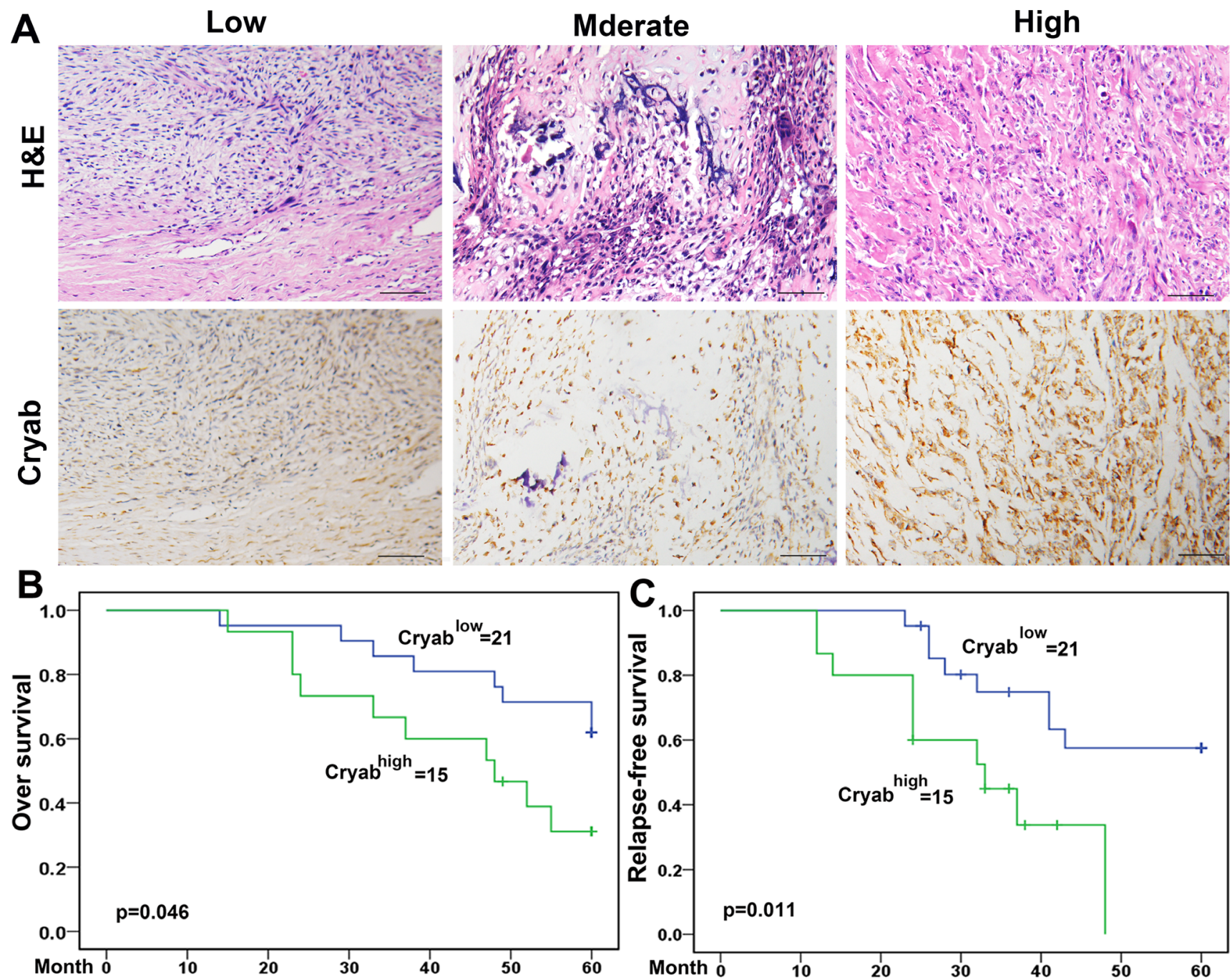

Figure 4: Cryab overexpression was associated with the poor prognosis of OS Patients. A. Immunoreactivity of Cryab protein was located in the cytoplasm of the carcinoma cells $($ bar $=200 \mu \mathrm{m})$; B. Prognostic significance assessed by Kaplan-Meier survival estimates and log-rank tests. Comparisons of OS and RFS by Cryab. 
Table 1: Correlation between Cryab expression and OS clinicopthological parameters

\begin{tabular}{|c|c|c|c|c|}
\hline \multirow{2}{*}{\multicolumn{2}{|c|}{ Parameter }} & \multicolumn{2}{|c|}{ Result of immunostaining (No. of patients) } & \multirow[b]{2}{*}{$p$} \\
\hline & & Cryab-negative $(n=21 / 36)$ & $\begin{array}{l}\text { Cryab-positive (n } \\
=15 / 36)\end{array}$ & \\
\hline \multirow[t]{3}{*}{ Age (yrs) } & & & & \\
\hline & $<19$ & 13 & 8 & \\
\hline & $\geq 19$ & 8 & 7 & 1.000 \\
\hline \multicolumn{5}{|l|}{ Gender } \\
\hline & Male & 12 & 11 & \\
\hline & Female & 9 & 4 & 0.054 \\
\hline \multicolumn{5}{|c|}{ Site of primary tumor $\dagger$} \\
\hline & Femur & 14 & 8 & \\
\hline & Tibia & 3 & 3 & \\
\hline & Humerus & 3 & 2 & \\
\hline & Pelvis & 0 & 1 & \\
\hline & Other & 1 & 1 & 0.103 \\
\hline \multicolumn{5}{|c|}{ Histologic differentiation $\uparrow \dagger$} \\
\hline & Osteoblastic & 10 & 13 & \\
\hline & Chondroblastic & 2 & 2 & \\
\hline & Fibroblastic & 5 & 0 & \\
\hline & Telangiectatic & 3 & 0 & \\
\hline & Other & 1 & 0 & 0.049 \\
\hline \multicolumn{5}{|c|}{ Enneking stage +} \\
\hline & I & 2 & 0 & \\
\hline & IIA & 6 & 1 & \\
\hline & IIB & 12 & 11 & \\
\hline & III & 1 & 3 & $0.001^{\mathrm{a}}$ \\
\hline \multicolumn{5}{|c|}{ Response to chemotherapy* } \\
\hline & Good & 15 & 7 & \\
\hline & Poor & 4 & 8 & \\
\hline & NA & 2 & 0 & 0.032 \\
\hline \multicolumn{5}{|l|}{ Metastasis } \\
\hline & Negative & 14 & 4 & \\
\hline & Positive & 7 & 11 & 0.019 \\
\hline
\end{tabular}

Note: $\dagger$ Femur vs. Tibia/ Humerus/Pelvis/Other; $\dagger \dagger$ Osteoblastic vs. Chondroblastic/ Fibroblastic/ Telangiectatic/Other; $\$$ I/ IIA $v s$. IIB/III; ${ }^{*}$ good $v s$. poor/NA; ${ }^{a}$ Fisher's exact probability.

was significantly correlated with high Enneking stage $(p=$ $0.001)$, a poor response to chemotherapy $(p=0.032)$ and metastasis $(p=0.019)$ compared to those patients with low expression of Cryab. However, additional clinical features, containing age, sex, and site of primary tumor were not significantly relevant to the Cryab expression.

\section{High level of Cryab was associated with poor prognosis of OS patients}

Up to the final follow-up, the 5-year overall survival and relapse-free survival (RFS) in the whole population were $69.44 \%$, and $62.35 \%$, respectively. The 2 - and 5-year overall survival in the Cryab ${ }^{\text {low }}$ group was apparently higher than that in the Cryab ${ }^{\text {high }}$ group (Figure 4B). The 2- and 5-year RFS in the Cryab ${ }^{\text {low }}$ group were apparently higher than those in the Cryab ${ }^{\text {high }}$ group (Figure 4C), indicating that Cryab expression predicts an unfavorable prognosis for patients with osteosarcoma. Univariate analysis showed that overexpression of Cryab, high Enneking stage, poor response to chemotherapy, and lymphatic metastasis were predictors of overall survival and RFS. Additional features containing age and sex had no prognostic significance for overall survival or RFS (Table 2).

\section{DISCUSSION}

In this study, we identified that the expression of Cryab was markedly increased in OS tissues compared with adjacent non-tumor tissues, and the high levels of Cryab were involved in invasion and metastasis of OS both in vitro and in vivo. Furthermore, we also confirmed 
Table 2: Univariate analysis of factors associated with OS survival and recurrence

\begin{tabular}{|l|l|l|l|l|}
\hline \multirow{2}{*}{ Variables } & Overall survival & \multicolumn{2}{|c|}{ RFS } \\
\cline { 2 - 5 } & Hazard ratio (95\% CI) & $\boldsymbol{p}$ value & Hazard ratio (95\% CI) & $\boldsymbol{p}$ value \\
\hline Sex (Male $v s$. Female) & $1.660(0.590-4.670)$ & 0.337 & $1.458(0.519-4.096)$ & 0.463 \\
\hline Age (years) $(<19 v s . \geq 19)$ & $1.009(0.983-1.037)$ & 0.506 & $1.012(0.986-1.040)$ & 0.381 \\
\hline Enneking stage (I/IIA vs. IIB/III) & $3.276(1.157-9.219)$ & 0.017 & $3.225(1.128-9.224)$ & 0.029 \\
\hline Site of primary tumor (Femur vs. other) & $0.977(0.378-8.2022 .524)$ & 0.962 & $1.077(0.417-2.784)$ & 0.879 \\
\hline Response to chemotherapy (good vs.poor/NA) & $3.029(1.125-8.153)$ & 0.023 & $3.324(1.471-7.531)$ & 0.004 \\
\hline Metastasis (negative $v s$. positive) $^{\text {Cryab }}{ }^{\text {low }}$ vs. Cryab $^{\text {high }}$ & $11.062(1.463-83.627)$ & 0.001 & $36.548(4.632-288.356)$ & 0.001 \\
\hline
\end{tabular}

Abbreviations and Note: OS, Osteosarcoma; RFS, relapse-free survival; 95\%CI, 95\% confidence interval; HR, Hazard ratio; Cox proportional hazards regression model.

that OS cell lines expressing high levels of Cryab had characteristic of increasing secretion of MMP9. The proliferation of OS cells did not varied by Cryab in vitro, however, the tumor volumes were large in groups with high Cryab expression, which might due to the difference in angiogenesis which is central for tumor growth [1416]. Clinically, we found that the elevated expression of Cryab correlates with poor survival and with disease recurrence of OS patients in the clinical setting. The above results favor the notion that Cryab makes a substantial contribution to tumor cell invasion and metastasis.

Numerous previous clinical studies documented that the high levels of Cryab endowed primary tumors with metastatic capacity [17], however, in head and neck cancer, an absence of Cryab has been reported to be a powerful marker for poor prognosis [10]. Our results indicate that high level of Cryab boosts tumor progression, which was supported by several lines of evidence. Firstly, the expression of Cryab is positively associated with metastatic potential of OS cells, and forced downregulation of Cryab correspondingly reduces the capacity for tumor metastasis and invasion both in vitro and in vivo. Second, we show that high expression of Cryab is associated with MMP-9 expression and secretion in OS cells. Lastly, we discover that elevated expression of Cryab occurs more frequently in various OS with poor prognosis-associated clinical variables, including high tumor staging and poor differentiation. Importantly, we also show that elevated expression of Cryab is correlated with poor survival and early disease recurrence in a cohort of OS patients. Thus, we concluded that high level of Cryab promoted OS progression.

Recently, Huang et al. reported that the elevated expression Cryab can induce hyperactivity of the ERK1/2 signaling pathway by forming a complex with $14-3-3 \zeta$ in human hepatocellular carcinoma [9], and Moyano et al. confirmed that high level of Cryab constitutively activates the MAPK kinase/ERK1/2 (MEK/ERK1/2) pathway in human basal-like breast tumors [8]. In line with previous reports, we also found that elevated expression of Cryab induces the activity MEK/ERK1/2 signaling in OS cells by employing RNA interference. Importantly, we show that the inhibition of ERK1/2 activity by U0126 led to reversal of the cancer phenotype conferred by high level of Cryab. While another report argued that Cryab inhibits the MEK/ ERK pathway in rabbit lens cells [18], it is not difficult to conclude that high level of Cryab can induce MEK/ERK signaling which is necessary for the expression of MMP-9 in OS cells.

Taken together, our results indicate that the high level of Cryab is a new adverse outcomes marker for OS patients and may be used as a new therapeutic target.

\section{MATERIALS AND METHODS}

\section{Cell lines and plasmids}

An hFOB1.19 (a human osteoblastic cell line) and four OS cell lines, including MG-63, U-2OS, Saos and HOS (acquired from the Cell bank of Chinese Academy, Shanghai, China), were conventionally cultured in RPMI 1640 (Invitrogen, Paisley, UK) supplied with 10 percent heat-inactivated fetal calf serum (FCS), 1\% L-glutamine, and penicillin/streptomycin $(10,000 \mathrm{U} / \mathrm{mL}$ and $10,000 \mu \mathrm{g} /$ $\mathrm{mL}$ ), and kept at $37^{\circ} \mathrm{C}$ in a humidified incubator under 5\% CO2. The pGPU6-GFP-vshRNA-Cryabs and pGMLVCryab was constructed by genomeditech biological company (Shanghai, China).

\section{Patients and follow-up}

The data of OS patients who underwent surgical treatment at the Second Affiliated Hospital of Nanchang University between January 2006 and December 2012 were summarized and reexamined. The pathological diagnosis was verified by two pathologists. OS patients who were still in clinical treatment or who were kept in touch by conventional telephone contact were gathered in our study. The frozen specimens were conserved by soaking the tissue samples in liquid nitrogen offhandedly after surgical excision, and then storage at $-80^{\circ} \mathrm{C}$. The samples that were estimated by pathologists were 
employed for the qRT-PCR and western blot test. Paraffinembedded osteosarcomas samples were conventionally prepared by the pathologist and kept in the department of pathology of our hospital. Written agreement from patients or their guardians was obtained and approved by the Nanchang University Ethics Committee. Clinicopathologic features of the present series of OS patients are shown in Table 1.

\section{RNA extraction and qRT-PCR}

Fifteen OS and their correspondent nontumorous specimens were employed to detect the Cryab expression, and the RNAs were extracted routinely according to the description elsewhere [4, 19]. The DNA amplification and revelation were accomplished by applying the ABI PRISM 7900 Sequence Detection System (Applied Biosystems, Foster City, CA). $\beta$-action was availed as an internal reference. Primers for Cryab were: 5'-CTTTGACCAGTTCTTCGGAG-3' and 5'-TCCGTGTTCAGCTGCTGGTA-3'; and $\beta$-action: 5'-AGAGCTACGAGCTGCCTGAC-3' and 5'-AGCACTGTGTTGGCGTACAG-3'. The PCR amplification were in accordance with the following steps: after denaturation at $94^{\circ} \mathrm{C}$ for $10 \mathrm{~min}$, then following by 40 cycles of denaturation at $94^{\circ} \mathrm{C}$ for $20 \mathrm{~s}$, annealing at $59^{\circ} \mathrm{C}$ for $30 \mathrm{~s}$, and extension at $72^{\circ} \mathrm{C}$ for $60 \mathrm{~s}$. The relative value of Cryab mRNA was analyzed according to the means of relative cycle threshold (Ct) [20]. This test was repeated three times.

\section{Immunoblotting and immunofluorescence}

Thirty mg protein extracted from there OS cell lines and samples were used for immunoblotting as described elsewhere [21, 22]. All the antibodies employed in our experiment were displayed in Supplementary Table 1. $\beta$-action (1:1000, cell signaling technology) was used as an internal reference. This test was repeated in triplicate. Immunofluorescence was performed as described elsewhere. Nuclei were counterstained with 4,6-diamidino2-phenylindole (DAPI, Vector Laboratories, Burlingame, CA). All the antibodies employed in our experiment were displayed in Supplementary Table 1.

\section{MTT assay, cell migration, and Matrigel $^{\mathrm{TM}}$ invasion assays}

Two hundred $\mu \mathrm{L}$ cells were loaded into a 96well plate (2000 cells/well), and cultured for 24,48 , or $72 \mathrm{~h}$, and then $20 \mu \mathrm{L}$ MTT solution was appended at the stipulated time and hatched for an additional $4 \mathrm{~h}$. Subsequently, the medium was replaced by $150 \mu 1 \mathrm{DMSO}$ with $200 \mu \mathrm{L}$ RPMI 1640, and the 96-well plate were rocked for $10 \mathrm{~min}$. Absorbance was measured at $490 \mathrm{~nm}$ to test the amount of viable cells in each well. This test was repeated in triplicate.

The scratch assay was applied to appraise cells motility ability. When the cultured cells blended up to $80 \%-90 \%$ in $24-w e l l$ plates, a scratch was maked by a plastic pipette tip across the cell surface. The remanent cells were cleaned triply to elute cell rubbish and incubated at $37^{\circ} \mathrm{C}$ with serum-free medium. At the certain time points, the scratching front were photographed and then compared.

The cell invasion assays were carried out in accordance with the previous reports [23]. This experiment was performed in triplicate.

\section{Gelatin zymography}

Gelatin zymography assay was performed as described [18, 24].

\section{Metastasis assays in vivo}

The OS cells (Including $2.0 \times 10^{6}$ shRNA-CryabMG-63 or U-2OS cells and shRNA-Mock-MG-63 or U-2OS cells) were suspended in $100 \mathrm{~mL}$ serum-free RPMI 1640 medium with Matrigel ${ }^{\mathrm{TM}}$ (BD Biosciences) $(1: 1)$, and then injected into the flank of nude mice (s.c.). The implanted tumors emerged at the injection site $8 \mathrm{~d}$ later. The implanted tumor volume (V) was reckoned according to the formula: $\mathrm{V}=0.5 \times \mathrm{L} \times(\mathrm{S})^{2}$, in which $\mathrm{L}$ and $\mathrm{S}$ are the largest and smallest perpendicular tumor diameters, respectively, Mice were sacrificed at 21 days after injection as previous reports. Serial lung sections were used to calculate the total number of lung metastases under the microscope as previously report $[5,25]$. Each group consisted of 6 mice.

\section{Construction of tissue microarrays and immunohistochemistry}

Tissue microarrays (TMA) were constructed by Shanghai Biochip Co. Ltd, Shanghai as reported elsewhere. Briefly, the histologically by hematoxylin and eosin staining sections from the all OS patients was reviewed by pathologists, and then the paraffin blocks were pre-stamped with the representative areas. The 1-mm-diameter cylinder tissues from two different areas in the araffin blocks near the non-cancerous border (named intratumor and peritumor, respectively; A total of 4 punches) were contained in each group, together with different compares, to ensure reproducibility and homogenous staining of the slides. Thus, 2 different TMA blocks were constructed, each containing 72 cylinders.

Polyclonal rabbit anti-human Cryab (1:200; Novus 
Biologicals, Cambridge, UK) was employed to determine the Cryab protein expression. Images were captured by the Leica QWin Plus v3 software. The intensity of staining was assessed as described. The two levels of Cryab intensity of were classified according to the mean area of positive staining, and the cutoff value was $50 \%$ of tumor section, the $\geq 50$ percent was positive, and negative was $<$ 50 percent.

\section{CONFLICTS OF INTEREST}

There is no conflict of interest.

\section{REFERENCES}

1. Guillon MA, Mary PM, Brugiere L, Marec-Berard P, Pacquement HD, Schmitt C, Guinebretiere JM, Tabone MD. Clinical characteristics and prognosis of osteosarcoma in young children: A retrospective series of 15 cases. BMC cancer. 2011; 11:407.

2. Fagioli F, Biasin E, Mereuta OM, Muraro M, Luksch R, Ferrari S, Aglietta M, Madon E. Poor prognosis osteosarcoma: New therapeutic approach. Bone marrow transplantation. 2008; 41 Suppl 2:S131-134.

3. Mirabello L, Troisi RJ, Savage SA. Osteosarcoma incidence and survival rates from 1973 to 2004: Data from the surveillance, epidemiology, and end results program. Cancer. 2009; 115:1531-1543.

4. Salah Z, Arafeh R, Maximov V, Galasso M, Khawaled $\mathrm{S}$, Abou-Sharieha S, Volinia S, Jones KB, Croce CM, Aqeilan RI. Mir-27a and mir-27a* contribute to metastatic properties of osteosarcoma cells. Oncotarget. 2015; 6:49204935. doi: 10.18632/oncotarget.3025.

5. Lamora A, Mullard M, Amiaud J, Brion R, Heymann D, Redini F, Verrecchia F. Anticancer activity of halofuginone in a preclinical model of osteosarcoma: Inhibition of tumor growth and lung metastases. Oncotarget. 2015; 6:1441314427. doi 10.18632/oncotarget.3891.

6. Kolb EA. Moving towards non-invasive assessments of prognosis in osteosarcoma. Pediatric blood \& cancer. 2010; $54: 497-498$

7. Muchowski PJ, Bassuk JA, Lubsen NH, Clark JI. Human alphab-crystallin. Small heat shock protein and molecular chaperone. The Journal of biological chemistry. 1997; 272:2578-2582.

8. Moyano JV, Evans JR, Chen F, Lu M, Werner ME, Yehiely F, Diaz LK, Turbin D, Karaca G, Wiley E, Nielsen TO, Perou CM, Cryns VL. Alphab-crystallin is a novel oncoprotein that predicts poor clinical outcome in breast cancer. The Journal of clinical investigation. 2006; 116:261270 .

9. Huang XY, Ke AW, Shi GM, Zhang X, Zhang C, Shi YH, Wang XY, Ding ZB, Xiao YS, Yan J, Qiu SJ, Fan J, Zhou J. Alphab-crystallin complexes with 14-3-3zeta to induce epithelial-mesenchymal transition and resistance to sorafenib in hepatocellular carcinoma. Hepatology. 2013; 57:2235-2247.

10. Yilmaz M, Karatas OF, Yuceturk B, Dag H, Yener M, Ozen M. Alpha-b-crystallin expression in human laryngeal squamous cell carcinoma tissues. Head \& neck. 2015; 37:1344-1348.

11. Yang J, Yang D, Sun Y, Sun B, Wang G, Trent JC, Araujo DM, Chen K, Zhang W. Genetic amplification of the vascular endothelial growth factor (vegf) pathway genes, including vegfa, in human osteosarcoma. Cancer. 2011; 117:4925-4938.

12. Kim HS, Lee Y, Lim YA, Kang HJ, Kim LS. Alphabcrystallin is a novel oncoprotein associated with poor prognosis in breast cancer. Journal of breast cancer. 2011; 14:14-19.

13. Egeblad M, Werb Z. New functions for the matrix metalloproteinases in cancer progression. Nature reviews Cancer. 2002; 2:161-174.

14. Shi GM, Ke AW, Zhou J, Wang XY, Xu Y, Ding ZB, Devbhandari RP, Huang XY, Qiu SJ, Shi YH, Dai Z, Yang XR, Yang GH, Fan J. Cd151 modulates expression of matrix metalloproteinase 9 and promotes neoangiogenesis and progression of hepatocellular carcinoma. Hepatology. 2010; 52:183-196.

15. Prevete N, Liotti F, Marone G, Melillo RM, de Paulis A. Formyl peptide receptors at the interface of inflammation, angiogenesis and tumor growth. Pharmacological research. 2015; 102:184-191.

16. Wang J, Wang Y, Wang S, Cai J, Shi J, Sui X, Cao Y, Huang W, Chen X, Cai Z, Li H, Bardeesi AS, Zhang B, Liu M, Song W, Wang M, Xiang AP. Bone marrowderived mesenchymal stem cell-secreted il-8 promotes the angiogenesis and growth of colorectal cancer. Oncotarget. 2015; 6:42825-37. doi: 10.18632/oncotarget.5739.

17. Gruvberger-Saal SK, Parsons R. Is the small heat shock protein alphab-crystallin an oncogene? The Journal of clinical investigation. 2006; 116:30-32.

18. Li DW, Liu JP, Mao YW, Xiang H, Wang J, Ma WY, Dong Z, Pike HM, Brown RE, Reed JC. Calcium-activated raf/mek/erk signaling pathway mediates p53-dependent apoptosis and is abrogated by alpha b-crystallin through inhibition of ras activation. Molecular biology of the cell. 2005; 16:4437-4453.

19. Ke AW, Shi GM, Zhou J, Huang XY, Shi YH, Ding ZB, Wang XY, Devbhandari RP, Fan J. Cd151 amplifies signaling by integrin alpha6beta1 to pi3k and induces the epithelial-mesenchymal transition in hec cells. Gastroenterology. 2011; 140:1629-1641 e1615.

20. Ke AW, Shi GM, Zhou J, Wu FZ, Ding ZB, Hu MY, Xu Y, Song ZJ, Wang ZJ, Wu JC, Bai DS, Li JC, Liu KD, Fan J. Role of overexpression of cd151 and/or c-met in predicting prognosis of hepatocellular carcinoma. Hepatology. 2009; 49:491-503. 
21. Wang W, Zhou X, Wei M. Microrna-144 suppresses osteosarcoma growth and metastasis by targeting rock1 and rock2. Oncotarget. 2015; 6:10297-10308. doi: 10.18632/ oncotarget.3305.

22. Saini P, Li Y, Dobbelstein M. Wee1 is required to sustain atr/chk1 signaling upon replicative stress. Oncotarget. 2015; 6:13072-13087. doi: 10.18632/oncotarget.3865.

23. Han K, Chen X, Bian N, Ma B, Yang T, Cai C, Fan Q, Zhou Y, Zhao TB. Microrna profiling identifies mir-195 suppresses osteosarcoma cell metastasis by targeting ccnd1. Oncotarget. 2015; 6:8875-8889. doi: 10.18632/ oncotarget. 3560 .

24. Jin ML, Park SY, Kim YH, Park G, Lee SJ. Halofuginone induces the apoptosis of breast cancer cells and inhibits migration via downregulation of matrix metalloproteinase-9. Int J Oncol. 2014; 44:309-18.

25. Xu JF, Pan XH, Zhang SJ, Zhao C, Qiu BS, Gu HF, Hong JF, Cao L, Chen Y, Xia B, Bi Q, Wang YP. Cd47 blockade inhibits tumor progression human osteosarcoma in xenograft models. Oncotarget. 2015; 6:23662-23670. doi: 10.18632/oncotarget.4282. 